September -2009

\title{
Teaching and Learning Against all Odds: A Video- Based Study of Learner-to-Instructor Interaction in International Distance Education
}

\author{
Jean-Marie Muhirwa \\ Equitas - The International Centre for Human Rights Education, Canada
}

\begin{abstract}
Distance education and information and communication technologies (ICTs) have been marketed as cost-effective ways to rescue struggling educational institutions in developing countries, particularly in sub-Saharan Africa (SSA). This study uses classroom video analysis and follow-up interviews with teachers, students, and local tutors to analyse the interaction at a distance between learners in Mali and Burkina Faso and their French and Canadian instructors. Findings reveal multiple obstacles to quality interaction: frequent Internet disconnections, limited student access to computers, lack of instructor presence, ill-prepared local tutors, student unfamiliarity with typing and computer technology, ineffective technical support, poor social dynamics, learnerlearner conflict, learner-instructor conflict, and student withdrawal and resignation. In light of the near death of the costly World Bank-initiated African Virtual University (AVU), this paper concludes by re-visiting the educational potential of traditional technologies, such as radio and video, to foster development in poor countries.
\end{abstract}

Keywords: Distance education; interaction; interactivity; sub-Saharan Africa; learners' support; Internet connectivity; pedagogy; learning theories; instructional design; traditional media

\section{Research Context}

During the sixties and the seventies, classroom interaction analysis became something of a catchphrase in educational research to the point that Tischer (1972) wondered if it had became "a new religion." It went on a declining path throughout the eighties before it returned to the limelight over the last two decades with the spectacular development of new information and communication technologies (ICTs) and their growing popularity in educational and training settings (Gunawardena, Lowe, \& Anderson, 1997; Hannafin, 1989; Hillman, Willis, \& Gunawardena, 1994). Most of these research efforts were conducted within similar geographical and socio-cultural contexts in developed or emergent countries. To date, most international distance education (IDE) projects in sub-Saharan Africa (SSA) seem to have been implemented based less on evidence from thorough needs/sector analyses and more on assumptions about their 
potential to rescue the battered educational and training systems in developing countries (AssiéLumumba, 2004; Sy, 2004). Although many policy papers on IDE have been drafted and material and equipment needs highlighted, a thorough investigation into the less tangible aspects of the process of IDE interaction remains scarce at best. IDE brings to bear a number of hidden sociocultural, historical, political, religious, linguistic, and philosophical distances and assumptions between the two communicating entities that are much harder to bridge than the tangible geographical distances and the 'digital divide' that IDE is supposed to bridge (Matthewson, 1994). In his definition of the transactional distance between learners and instructors, Moore (1997) argues that the notion of distance in DE is not simply a geographic separation of learners and teachers but is, more importantly, a "pedagogical concept." As he puts it,

It is a concept describing the universe of teacher-learner relationships that exist when learners and instructors are separated by space and/or by time. This universe of relationships can be ordered into a typology that is shaped around the most elementary constructs of the field - namely, the structure of instructional programmes, the interaction between learners and teachers and the nature and the degree of self-directedness of the learner. (p. 22)

Yet empirical evidence and past research suggest that even in traditional face-to-face teaching and learning situations, teachers have a natural tendency to use their own dominant cultural patterns and references (Heath, 1983), which overlook students' alternative ways of knowing (Moodie, 2003).

\section{IDE Projects in Sub-Saharan Africa (SSA)}

Two decades ago, the spectacular development of ICTs revolutionized many areas of the economy and day-to-day life in developed countries. Expectations ran high in the educational sector not only in developed countries but also in developing countries. Technology-based education and training was deemed to be the most cost-effective, cost-efficient way of solving many of the endemic problems in education and training. Nowhere were expectations higher than in SSA. Donor countries and international organizations advocated "bridging the digital divide" as a developmental and ethical necessity to aid countries in SSA to alleviate poverty. Improving education and training in SSA thanks to the delivery of quality IDE or training programmes from some of the most prestigious institutions in the world was given high priority. The study reported here was conducted in Mali and in Burkina Faso, two IDE program recipients, and in Canada, a program provider. Participants were students, administrators, tutors, and technical assistants form the African Virtual University (AVU) and from the Université numérique francophone mondiale (UNFM). 


\section{The AVU}

Funded by the World Bank, the AVU pilot project started in 1997. Fifteen higher education institutions (mostly Anglophone) participated in the initial phase. The AVU's stated lofty goal "to contribute to efforts to improve education in Africa by harnessing the power of modern information and communication technologies and to position Africa in the wider knowledge society" triggered some controversy (see Amutabi \& Oketch, 2003; Munene, 2007). From its head office in Washington, the AVU delivered various undergraduate and short capacity-building programs from Western universities to participating universities in SSA. During its two initial phases, it used a TV-like studio fully equipped to produce multimedia content (text, still images, audio, and video). The delivery system comprised a combination of satellite and Internet technology to allow a one-way transmission of courses.

As of 2003, the AVU transitioned from a World Bank project based in Washington to an African intergovernmental organization headquartered in Nairobi (Kenya). Programs in computer science, in journalism, and in business administration from Western universities were delivered to higher education institutions in SSA via an Internet delivery platform (Interwise), using satellite antennas. French-speaking countries jumped on the AVU bandwagon in 2005. More than a dozen higher education institutions subscribed to a bachelor's program in computer science offered by a Canadian higher education institution through the AVU.

\section{The UNFM}

Mali and Burkina Faso were two particularly interesting research sites. Coincidently or not, the UNFM was launched three months prior to the beginning of the AVU's bachelor's program in computer science in these two former French colonies. Targeting francophone higher education and training institutions, the UNFM initiative was stewarded by Cheikh Modibo Diarra, the Malian astrophysicist whose contract as AVU's CEO had been abruptly terminated. The UNFM was co-funded by the Fondation pour l'inovation politique (Fondapol), a French foundation and think tank, and the Pathfinder Foundation for Education and Development, created by Dr Diarra. The clear intention that motivated the creation of the UNFM was to position it as a competitor to the AVU (Loiret, 2005). The UNFM pilot project offered training sessions in tropical medicine to in-service nurses in Mali and in Burkina Faso.

\section{The Delivery Method}

The most conspicuous peculiarity of IDE programs destined to SSA is the fact that given the poor infrastructure and lack of ICT equipment within African households the "anytime, anywhere" slogan could not apply. Registered students had still to commute to campuses. In the case of the AVU, when the Internet connection was good, courses consisted of synchronous lectures delivered from Canada. Although the narrow Internet bandwidth did not allow the lecturer's image to be displayed, learners could hear the tutor's voice synchronously while he or she explained PowerPoint slides projected onto a screen situated on the front wall in the classroom. 
Using a hand-like pointer, lecturers could underline, circle, or point to particular items on the slide while explaining course materials. The learners could interact with lecturers using a headset with a microphone, which was connected to the one computer in the classroom. Thus, they could ask questions or answer the tutors' questions synchronously. Given frequent instances of Internet disconnections or power outage, the synchronous version of the delivery was backed up by a WebCT site, where students could find course materials they missed.

The UNFM's delivery system was slightly different. One reputable French health institution provided and delivered lectures. Although students could see their instructors on the screen and hear their voices, no means for oral feedback were provided. As one participant put it, "We watch as if we were watching a TV show." Students could only interact with their distant instructors by typing in their questions or answers using the one computer in the classroom.

This was also the solution AVU students resorted to in the many instances of poor sound quality due to the narrow Internet bandwidth. Given the combination of students' awfully poor typing skills and the novelty of the subject matter, even short interactions with distant tutors would take disproportionate amounts of time and be subjected to numerous distortions. In the case of the UNFM, when the connection did not allow either form of oral or written interaction, back up CDROM copies were sent by mail to the students. It could take a few weeks before students got acquainted with the learning materials.

\section{Research Questions}

This study explores the interaction process between two groups in IDE contexts, namely lecturers from developed countries (France and Canada) and their students in SSA, who are separated by geographical and other differences, including cultural and linguistic. Given the fact that past studies of interaction focused mostly on interaction within similar cultures on the one hand and the various distances involved in IDE on the other hand, studying international teacher-learner interaction would contribute to the understanding of some of the most important aspects of IDE. According to Yacci (2000), educational interaction is a message loop from the learner's point-ofview, which has two outputs, content learning and affective benefits, and mutually coherent messages from both sides.

Using a triangulation of quantitative and qualitative analysis from video analysis of classroom interaction and follow-up, in-depth interviews with teachers, students, and local tutors, this study analyzed lecturer-to-learner interaction and how it influences learner-to-learner and learner-tolocal tutor interaction.

The following questions guided the study:

- What are the main obstacles to quality instructor-to-learner interaction in IDE destined to SSA?

- How do these obstacles impact learner-to-learner and learner-to-local tutor interaction? 
Given the scarcity of sound theoretical and empirical foundations to inform policy makers, administrators, and IDE practitioners, it is hoped that findings from this study will be a worthwhile contribution to the understanding and, ultimately, the improvement of IDE.

\section{Theoretical Framework: Interaction, Interactivity, and Socio-Cultural Theory of Learning}

Over the last two decades, the rising tide of new information and communication technologies (ICTs) gave impetus to an increased interest in studying interactivity, and this created confusion between interaction and interactivity, especially in educational and training settings (Reeves, 1999). Although the latter is more related to technology-based communication, the former is more encompassing. It can be applied to computer-based communication (as in human-computer interaction or voice-to-machine interaction) as well as to more traditional forms of human communication. But the two concepts are commonly used interchangeably.

Moore (1989) has classified interaction according to the nature of the entities involved in the interaction process. He identified three main types of interactions: learner-to-instructor interaction, learner-to-learner interaction, and learner-to-content interaction. Because computermediated communication plays an important role in DE, Hillman, Willis, and Gunawardena (1994) later underscored the importance of learner-to-interface interaction.

The seminal work of Vygotsky (1978) was an important contribution to the understanding of the role of interaction in children's learning. Vygotsky theorized that learning consists of a dialectical process of problem-solving experiences shared with someone else (parents, teachers, or peers) through interaction. Subsequent research efforts confirmed how teacher-to-student interaction plays a paramount role in learning and academic achievement (Heath, 1983; Rogoff 1995). Further research pertaining to DE concurred that quality interaction plays a crucial role in students' learning, achievement, satisfaction, and participation (Fulford \& Zang, 1993; Insung, Seonghee, Cheolil, \& Junghoon, 2002).

More recently, Kress (2003) espoused the socio-cultural theory with respect to new technologies. $\mathrm{He}$ argued that technologies are culturally and socially bound modes of representation and communication. In order to convey meaning in specific cultures, their affordances are subject to syntax and grammatical rules that make them understandable in the culture of local people. According to Kress (2003), "Cultures work with these material affordances in ways which arise from and reflect their concerns, values and meanings." (p. 45). This is consistent with the Vygotskyan socio-cultural theory of learning.

\section{Learning Styles}

Socio-cultural learning theory underscores how culture and cultural artefacts teach people what to think and how to think by providing them with tools of intellectual adaptation. Thus, they play an 
important role in shaping students' learning styles. For example, students from SSA, arguably the most oral culture in the world, will be more likely to learn through oral interaction than their Western instructors who were shaped by a more visual culture. As a consequence, instructors and learners will face a learning style mismatch, which, if not addressed, will hinder learning. As Jorgensen (2006) puts it, when it comes to learning in diverse or cross-cultural contexts, "one size does not fit all."

\section{Multimedia Learning Theories}

One of the most remarkable features of multimedia learning is the potential it offers to use both auditory and visual modalities to convey meaning and enhance learning. Taking into account the constraints of working memory and its complex relationship with long-term memory during the process of retrieval, storage, and retention of information for learning purposes, cognitive psychologists have developed a number of theories that enunciate the guidelines for optimal integration of verbal and visual information for learning. Over the last thirty years, multimedialearning theories have contributed to the improvement of our understanding of conditions under which the design and delivery of learning materials can be successful. For example, according to dual-coding theory (Clark \& Paivio, 1991), presenting information both in visual and verbal forms enhances learning and recall. Cognitive load theorists (Leahy, Cooper, \& Sweller, 2004; Sweller, Van Marriënboer, \& Pass, 1998) further posit that problem-solving and learning are enhanced or impaired depending on how cognitive resources are focused and used according to the limited processing capacities of working memory. As Chandler and Sweller (as cited in Leahy, Cooper, \& Sweller, 2004) summarize, "Traditional methods of instructional design based upon visual elegance, common sense, and convenience are rendered ineffectual” (p. 91). In the following pages, I analyze to what extent this body of theoretical frameworks has been taken into account in the design and the delivery of IDE projects in SSA.

\section{Methods}

\section{Data Collection}

The set of data used in this study was collected from December 2005 to February 2006. Participants were university students from Mali and Burkina Faso taking an undergraduate IDE programme in computer science offered by a Canadian higher education institution and an inservice nurse training programme in tropical medicine offered by one French health institution. Prior to undertaking the fieldwork, I had the opportunity to live and work in Mali and Burkina Faso. Thus, I had a chance to witness the early implementation stages of the two IDE projects in both countries. I created rapport with potential participants for twenty months prior to the beginning of data collection. Data were videotaped using a Sony DCR-TRV 510 Digital 8 video camera equipped with a sensitive built-in microphone and a foldable 5-inch colour screen monitor. The fact that the camera was equipped with a night shot option that provided perceptible black and white images even in very low luminosity was very helpful. Most of the time, dark 
curtains had to be closed in order to allow the students a better view of the PowerPoint slides or images on the central screen in their classrooms.

Twenty hours of Hi 8 videotape footage were recorded. A headset was used to monitor sound quality. The video and tape recorder functioned on battery most of the time. This allowed me more freedom to move around if necessary while reducing obtrusiveness. In order to preserve participants' anonymity, the video camera was placed on a tripod in the back of the classroom. The camera position, shooting from the back with the learners in the foreground while at the same time showing the lecturers' actions on the screen at the front of the classroom, was consistent with this study's focus on lecturer-to-student interaction (Erikson, 2006). Various camera movements (zoom in/zoom out; right/left panels) allowed me to focus on any point of the classroom where the interaction was happening. After shooting, the more significant instances of interaction were selected and shown to small groups of three or four students on my MacIntosh PowerBook G4 laptop computer screen, which was connected to the camcorder by a firewire cable. Students' comments were recorded on audiocassettes. The same procedure was used with lecturers in Canada.

\section{Data Analysis}

This study followed a "whole-to-part" or inductive approach to video data analysis (Erikson, 2006; Nastasi, 1999). The 20-hour (72,000-second) videotaped materials were reviewed in real time on a PowerBook G4 laptop computer screen connected to a TRV 550 Sony camcorder by a firewire cable. Clips of interactions relevant to this study's research questions were isolated and saved in Quick Time video format in such a way as to allow further analysis using HyperResearch, a qualitative analysis package.

Given the frequent Internet disconnection and power failures, the continuous clock feature provided complementary information about time lapses between disconnections or power outages. Following Erikson's (2006) inductive procedure and Nastasi's “videotaped critical incident" approach $(1999$, p. 23), instances of interaction located during the first integral viewing were isolated and saved in QuickTime Player format, which was compatible with HyperResearch.

Given this study's research questions, all instances of tutor-to-learner interaction during the recorded 20 hours were considered as "videotaped critical incidents" to be further analyzed. Straight lectures with no observable lecturer-to-learner interaction were not considered for analysis.

\section{Results}

\section{A Quantitative Overview}

The first step of the analysis consisted of establishing a quantitative overview of the interaction time. Table 1 below illustrates the results from a preliminary analysis yielded by the time code 
counter and the camera clock readings from the selected video clips. It shows that during 20 hours, there were little more than 28 minutes of instructor-to-learner interaction at the AVU (1, 721 seconds or $2.3 \%$ of the interaction time) and 69 minutes at the UNFM (4,147 seconds or $5.7 \%$ of the interaction time). In addition, Internet disconnections stand out as the main challenge to lecturer-to-learner interaction. With respectively $1.2 \%$ and $3 \%$ at the AVU and at the UNFM, the Internet connection problems occur more often than any interaction. The table shows also that most of the time lecturers use the very limited interaction opportunities to instruct more or to allow students to explain (1.1\% for the AVU and $1.4 \%$ of the time at the UNFM).

The overall students' participation is limited to a mere $0.4 \%$ of the interaction time for the AVU and $1.3 \%$ for the UNFM. Furthermore, these results show that part of this precious interaction time is wasted in disagreement between students $(0.3 \%$ of the time at the AVU and $0.4 \%$ at the UNFM).

Table 1

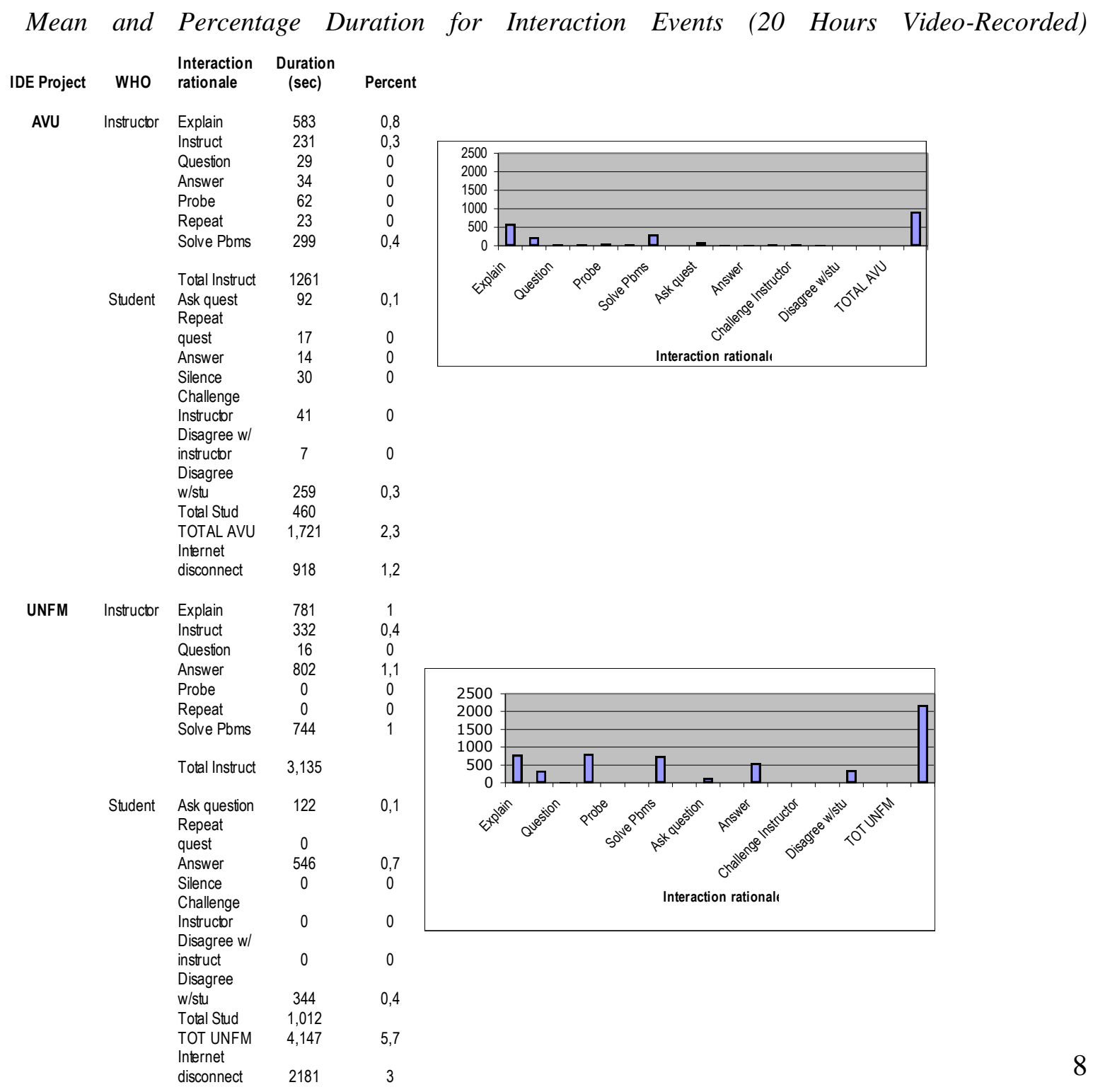




\section{Qualitative Analysis}

The coding process used the HyperResearch qualitative analysis package. Its video analysis feature allows the analyst to select parts of the video materials under scrutiny and assign them codes. Particular aspects of interaction consistent with the research questions were thus selected and coded. The main findings from qualitative analysis of the video footage largely corroborated the quantitative findings. They are discussed below.

\section{Internet Connectivity}

There are numerous consequences to the very high frequency of Internet disconnections the quantitative data showed above. They result in a variety of interaction problems such as poor sound quality, poor PowerPoint slides or image readability, long question-response lag time, question-answer overlap, or numerous repetitions before students or teachers make themselves understood. These technology-related problems impair instructor-to-learner interaction. Even during those periods when the Internet connection is supposed to be working, its narrow bandwidth does not allow clear instructor-to- learner communication. This results in a waste of time, and sometimes signs of frustration if not exasperation from both students and instructors are observable. Consider the following exchange between the AVU computer science instructor and one of his students in Ouagadougou:

1. Student: There is another question... When you have a polynomial function and... [cut off]

$(15 \sec 12)^{1}$

2. Instructor: What kind of function do you want to find?

$(18 \sec 10)$

3. Student: If I have a polynomial function... [Cut off]

(19 $\sec 38)$

4. Instructor: Do you want to find it in MathLab ${ }^{2}$ ?

$(20 \sec 11)$

5. Student: No, no, Monsieur. It does not have anything to do with MathLab

(16 sec 23)

6. Instructor: IS IT A FUNCTION IN MATHLAB OR...?

(13 sec 56)

7. Student: IT HAS NOTHING TO DO WITH MATHLAB, MONSIEUR

(13 sec 39)

8. Instructor: Okay...

(10 sec 34)

9. Student: When I have a polynomial function...[Cut off]

\footnotetext{
${ }^{1}$ Time is expressed in minutes, seconds, and one-hundredth of seconds. The time between brackets represents the response lag time when it is situated between two lines of replies. It represents the duration when situated at the end of the reply. The duration was not mentioned for short replies of less than 10 seconds.

${ }^{2} \mathrm{~A}$ programming language that is believed to be faster than traditional languages such as $\mathrm{C}$ and $\mathrm{C}++$.
} 
$(15 \sec 19)$

10. Instructor: $\quad$ YES, GO ON. I'M LISTENING TO YOU ...

$(17 \sec 26)$

11. Student: And then I want to derive two other functions from the original functions...Is that all I need? (20 sec 14)

12. Instructor: Yes, that's all you need... It depends on what you want to do with the function [...] Have I answered to your question? (5 min $25 \mathrm{sec} 19$ ) $(9 \sec 58)$

13. Student: Yes, Sir. Thank you very much.

As the excerpt shows, the quality of synchronous online communication is very poor. It took eleven replies and almost three minutes (178 seconds) before the instructor understood the question he was being asked. Sometimes, the Internet connection was so bad that IDE lecturers would have no other choice than to stop teaching altogether even though the Internet was supposed to be working.

The capitalized replies in the excerpt above stand for a heightened tone of interaction betraying frustration or exasperation, which poorly serves content learning and affective benefits, the necessary outputs of educational interaction (Yacci, 2000). This situation does not sit well with multimedia learning theories, dual coding theories, and the importance of quality feedback from students' questions, discussed earlier in this text. Moreover, these technology-related problems were predictable. It is well documented that the African continent remains the most unwired part of the world. For example, although Africa has approximately $12 \%$ of the world's population, it has only $2 \%$ of the global telephone network (Darkwa \& Mazibuko, 2000). In addition, most of its internal communications (video, voice, data) have to transit through Western countries, rendering the cost of communications more expensive than anywhere else in the world, and this is particularly true for higher education institutions, as explained by Gakio (2006):

The average African university has bandwidth capacity equivalent to a broadband residential connection available in Europe, pays 50 times more for their bandwidth than their educational counterparts in the rest of the world, and fails to monitor, let alone manage, the existing bandwidth for educational purposes. As a result, what little bandwidth that is available becomes even less useful for research and education purposes. (p. 3)

This technological landscape makes the kind of synchronous IDE instruction offered by the AVU and the UNFM seem inappropriate in SSA. 


\section{Poor Pedagogy and Human Touch}

In addition, instructors appear to be unprepared to handle this kind of situation. For example, as mentioned earlier in this text, students at the UNFM could only listen to and watch their lecturers on the screen without any possibility to interact with instructors orally. This does not make them less vulnerable to the poor quality of the Internet connection, and their instructors do not seem better prepared to handle the situation than AVU instructors. Confronted with a technical problem, which prevented her from showing the PowerPoint slides that constituted her only teaching material, one UNFM instructor candidly told her students,

I am a little bit... I do not even have a print copy to back me up. I am a bit... I am speechless... This problem will be fixed! We will fix it! So, while we are trying to fix this problem, you can use this time to discuss health policy matters in your two countries. (Tape \#1, UNFM Bamako, 14/12/2005, Time Code: $11: 16: 18-11: 18: 31)$

As the video footage shows, it took 38 minutes before the problem was fixed. From this point on, in an attempt to catch up on time, the instructor used the remaining 23 minutes for a straight lecture with no interaction whatsoever with the students. As a result, the learners did not seem to pay any attention to the lecture. Some of them were chatting; others took a nap or played with computer screens sitting in front of them. Only a few struggled to follow the straight lectures when the Internet connection allowed it. UNFM students in Bamako deplore the pedagogic situation as follows:

$\mathrm{Au}$ niveau pédagogique nous trouvons des faiblesses notamment en dispensation des cours magistraux par des professeurs occidentaux. Pas de dialogue direct entre formateurs et formés; pas d'encadreurs du côté malien sur le terrain.

[On a pedagogic level, we find weaknesses in the way foreign lecturers carry out their DE teaching. There is no direct interaction between the lecturers and the students and there are no local tutors in Mali. (Focus group interview, Bamako, 15/12/2005)]

The lack of local tutors is one of the students' most serious preoccupations in the two IDE projects. Yet, DE literature insists on the importance of the tutor in the student support process (Dhanarajan, 2001; Lentell, 2003). In Ouagadougou, UNFM students share the same view as their counterparts in Bamako but they emphasize "le manque de chaleur humaine entre enseignants et enseignés" [the lack of human touch between students and their instructors].

The lack of social presence and human touch is a problem that has dogged online DE for many years. Even in developed countries' learning environments, more attuned to individualism, Gunawardena and Zittle (1997) suggested that social presence is a predictor of learners' 
satisfaction in online learning environments. This can be assumed to be even more the case with students from SSA, who are familiar with a collective lifestyle within extended families in villages and in urban settings.

Some AVU students liken their lectures to "listening to the radio with a high level of interference" [C'est comme écouter la radio avec beaucoup de parasites]. One AVU official goes even further in deploring the pedagogic approach taken by his institution and warns against its dire pedagogic consequences on students' learning:

There is an unfortunate and ultimately damaging perception that the process of developing e-Learning simply requires that existing teaching materials (usually antiquated lecture notes) be digitized and put online. This 'digital dumping ground' will result in the development of extremely poor quality online teaching and learning and will contribute nothing to higher education in Africa nor to the AVU's mission. (Bateman, 2004, p. 5)

\section{Students' Unfamiliarity with Technology and Poor Support}

At the UNFM, students can interact with their instructors only by typing their questions or answers. This is also the case at the AVU in the many instances when the sound quality is too poor to allow synchronous oral communication. One instructor with exceptional typing skills says sound problems forced him to practice a mixed form of communication with his students. He frantically types in every word he utters. He says this form of interaction is less frustrating for him and for the students, especially when sound quality is poor. Students say they appreciated this instructor's strategy.

Nonetheless, this brings to the fore the problem of students' poor typing skills. For example, it took 145 seconds (more than two minutes) for UNFM students in Bamako to type the following three short questions (23 words):

- Qu'est ce qu'un vaccin thymo-indépendant? [What is a thymoindependent vaccine?]

- Qu'est ce qu'une valence vaccinale? [What is a vaccine valence?]

- Que veulent dire les procedures de contrôle de qualité vaccinale? [What do vaccine quality control procedures mean?]

The typing speed of UNFM students could be estimated at 9 words-per-minute (WPM). Given this poor typing performance, the fact that at the UNFM instructor-to-student interaction happens only in writing could explain why it looks like the UNFM has more than twice the interaction time at the AVU (see Table 1 earlier in the text). 
At the AVU in Ouagadougou, it took one student 153 seconds to type in the following 18 -word definition of the exploitation system of a computer:

"Un système d'exploitation est utilise pour gérer des logiciels, piloter l'ordinateur, gérer l'interface entre l'utilisateur et le materiel."

[An exploitation system is used to coordinate software, pilot computer, and manage the interface between the computer and its user.] (Figure 1 is an illustration of this episode.)

This performance of 7 WPM is even lower than that of the UNFM. But contrary to the UNFM, most AVU instructors do not rely exclusively on written interaction. They give precedence to oral interaction despite its numerous problems.

Karat, Havelson, Horn, and Karat (1999) estimate that the performance of the average computer user is 33 WPM for transcription and 19 WPM for composition. Isokoski and Linden (2004) found that working in a foreign language lowered text transcription performance. They documented that Finnish people were 16\% slower and made more typing errors while typing English than while typing Finnish. This phenomenon might be at play with students from SSA. Although they have a good command of the French language, Voltaire's language remains foreign to them.

In addition, the majority of IDE students confessed they had the opportunity to use a computer keyboard for more than half an hour for the first time when they started their IDE program. Taken together, these considerations might explain why IDE students in SSA have less than half the typing performance of the average computer user.

More importantly, from a pedagogy standpoint, it should be noted that the questions and answers above belong to the lowest levels of Bloom's Taxonomy of Educational Objectives (1956). They are about knowledge and comprehension. Thus they fall short of addressing the higher levels of application, analysis, and synthesis that professionals in SSA need so badly.

\section{Poor Social Dynamics, Dominance, and Arrogance}

The interaction problems discussed above have a negative impact on classroom social dynamics and collaboration. The fact that there is only one central computer equipped to allow lecturer-tolearner interaction in each classroom triggers competition among the students for control of the interaction process. Lecturers do not seem to question the fact that they interact with the same few students over and over. These self-appointed students ask questions or answer the instructor's questions as if they were mandated by their classmates to do so, which is far from being the case.

At the UNFM and at the AVU, a small group of two or three students sits around the central computer and controls the interaction tools connected to it, such as the microphone, the headset, and the keyboard. This dominant group of students impose themselves on the rest of the class. At 
the AVU and at the UNFM, all the dominant students are men. They had some familiarity with the use of computers before they started the IDE program or they were sophomores. In the absence of local tutors to moderate the interaction process, this group of students behaved as if they were the legitimate class representatives.

They set up the central computer either in the front row or in the back of the classroom (see Figure 1) and they seemed not to care about the opinion of the rest of the class. They did not allow their classmates the time necessary to ask questions or clarify their answers. The rest of the class seemed resigned to the situation, but sometimes there were sparks of disagreement and conflict.

\section{Learner-to-Learner Disagreement/Conflict}

Sometimes dominant students' arrogance sparked verbal arguments or gestures such as microphone grabbing. Consider the following interaction from the video footage:

1. Instructor:

2. Dominant student 1:

3. Female student: (Speaking to dominant student 2):
Is... Is...the explanation clear?

Yes, sir, it is very clear. Thank you!

No, it is not. I have a question...

I wanted to ask him [the distant instructor] if he could demonstrate (...) [The group of dominant students cut her off]

4. Group of dominant students (in chorus): Yéééééééé + disapproving murmurs from the rest of the class

5. Female student (protesting and frustrated): WHAT? DON'T I HAVE THE RIGHT TO ASK A QUESTION? (Tape 3, AVU Bamako, 16-12-05)

The female student's comments are followed by more murmurs. Apparently frustrated, the female student bounced back on her chair, pulled her veil over her face, and withdrew. The disagreement above lasted one minute and a half. Oblivious, the distant instructor carried on with his lecture. In Bamako, nobody was listening to him. Students were busy arguing. The same thing happened in Ouagadougou. Students argued without paying attention to the lecture that was going on. Sometimes, instead of arguing, students who had something to say to the instructor would walk towards the central computer, grab the microphone from the hands of one of the dominant students, and ask their question. This happened a few times after one of the dominant students had misinformed the instructor that everything was clear and there were no questions. 


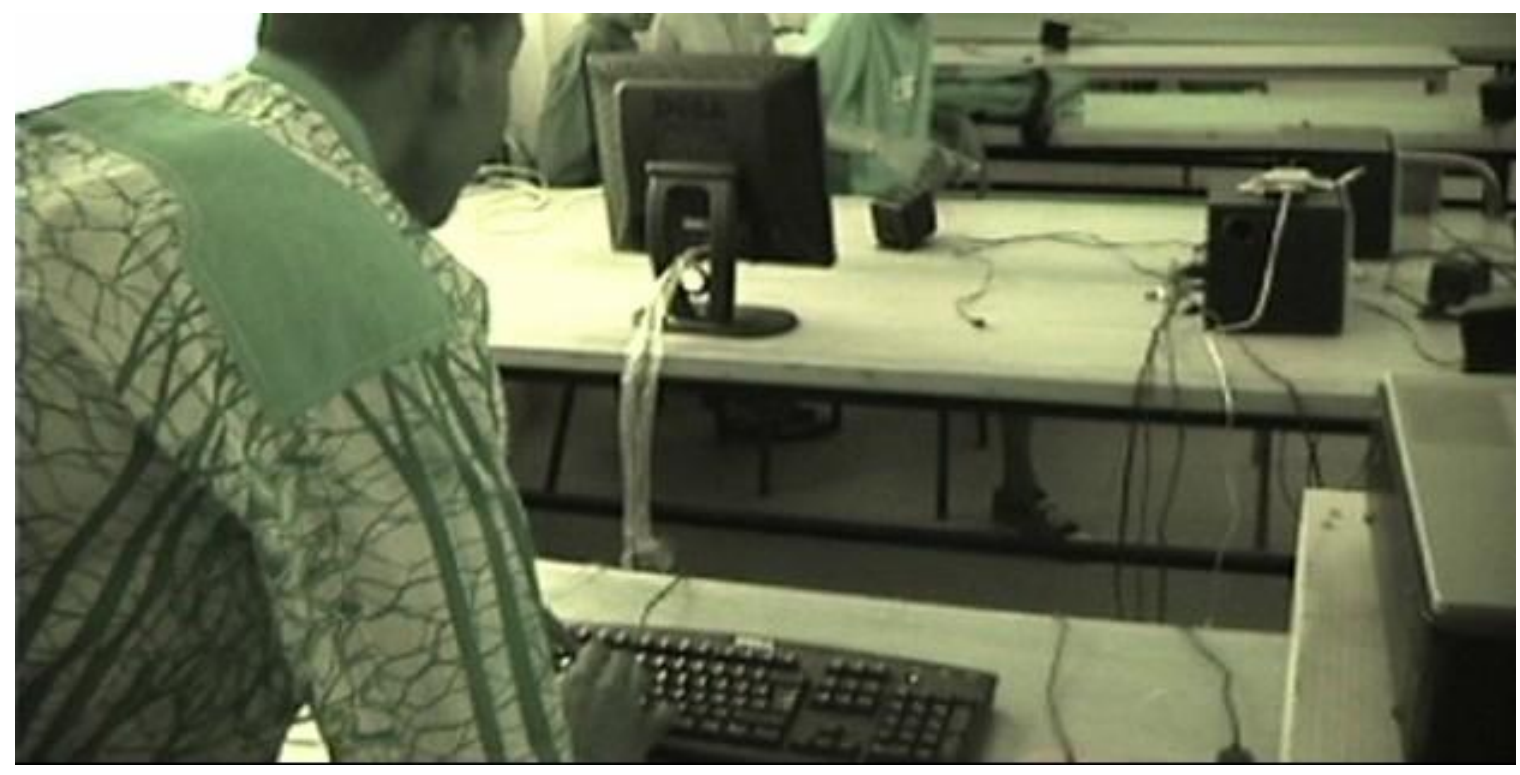

Figure 1. A partial view of the DE classroom setting at the AVU-Ouagadougou in Burkina Faso, where a student is typing an answer.

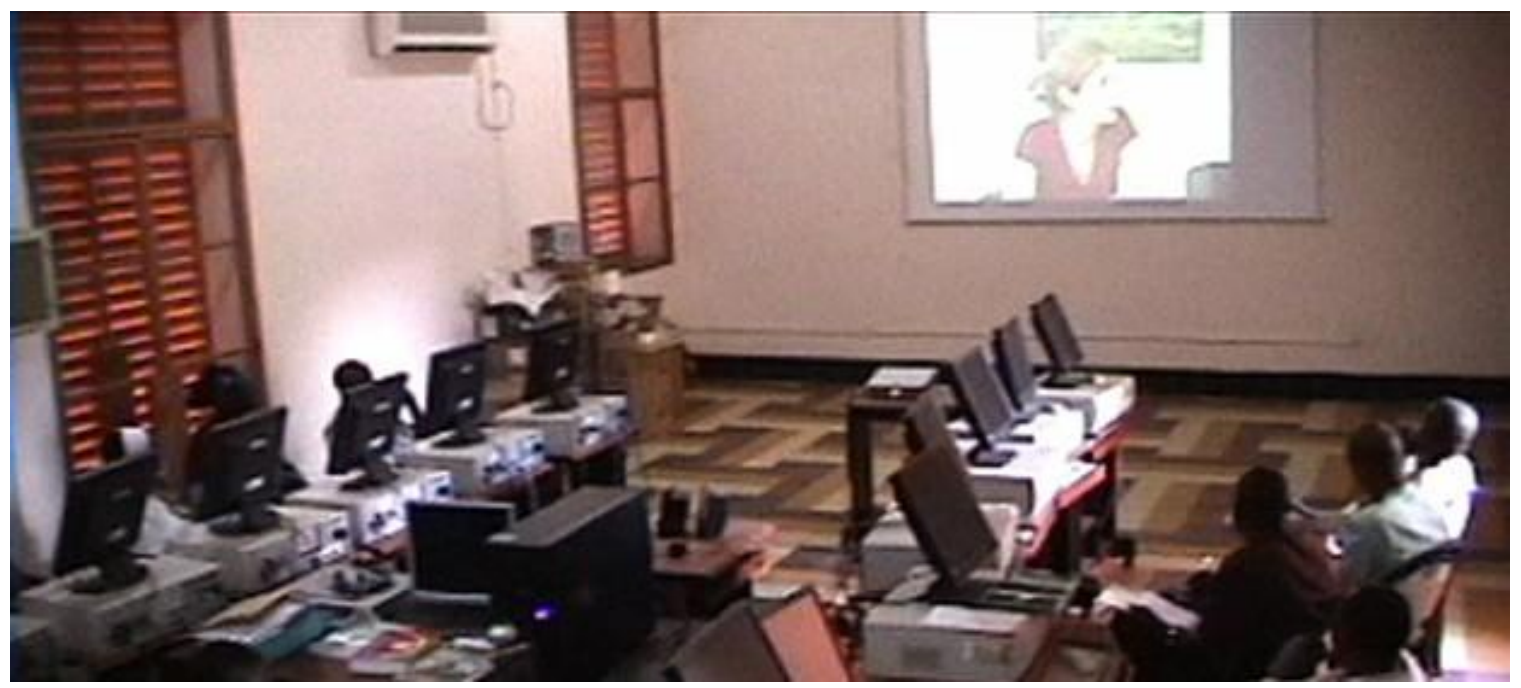

Figure 2. A partial view of the DE classroom setting at the UNFM-Bamako in Mali. 


\section{Learner-to-Instructor Disagreement: Withdrawal and Silent Resignation}

One student stepped forward to the microphone to ask the following question:

1. Student: How could you perform this operation with MathLab?

2. Instructor: Yes, you could perform it with MathLab.

This laconic answer triggered laugher, and the students' body language expressed scepticism. Because of the long response lag time, the answer from the instructor came when the student who had asked the question was already walking back to his seat. He threw his hands in the air in discouragement. He turned around and came back to grab the microphone from one of the dominant students:

3. Student: How?... How? Please, sir...

The instructor attempted an explanation that lasted 3 minutes and 31 seconds.

4. Instructor: You could do the operation with MathLab if the two operations are compatible (...) Have you understood?

5. Student: We didn't understand a thing, Monsieur. That was too fast.

The explanation that followed lasted 15 minutes and 25 seconds

6. Instructor: In MathLab for example (...) Is it clearer now?

7. Student: Yes, sir, it is clearer.

Despite this answer, the body language of the majority of the students continued to suggest otherwise (disapproving head shaking and index finger waving). While the student interacting with the instructor was busy reassuring the instructor that his explanations were clearer, the disagreement between students became raucous. Many students angrily voiced their frustration and blamed the student who had interacted with the instructor for misrepresenting their opinion. A few students supported him. The distant instructor who did not have a clue about what was going on in the classroom in Ouagadougou was content with his interlocutor's feedback and carried on to the next activity.

\section{Questioning Local Tutors' Preparedness and Students' Collaboration}

At the UNFM, although there is no direct oral instructor-to-learner interaction, disagreements occur most times during the loud reading of written answers from instructors. The following exchange happened between one female student and the local tutor:

1. Female student: You are reading too fast. We do not understand what you are reading.

2. Local Tutor: WHAT ARE YOU COMPLAINING ABOUT? I AM TRYING TO HELP YOU OUT AND YOU FIND MATTER TO COMPLAIN ABOUT! 
3. Female student: (inaudible but apparently protesting) (UNFM Bamako, tape 1bis, $10: 12: 55 \mathrm{am})$

Although the UNFM training program targets in-service professional nurses, it is important to point out that the so-called 'local tutor' involved in the exchange above was a recent graduate from the local engineering school! By his own admission, he did not understand many of the medical concepts and terminology used in the courses. Thus, his role was reduced to helping students to use the central computer when typing in their questions and/or answers and reading answers to students' questions from the distant instructors.

At the AVU campuses in Mali and in Burkina Faso, the few available local tutors are graduate students in computer science. From a theoretical point of view, they are well qualified to support students in their learning task. But, as the following student-to-local tutor interaction episode shows, they are not always willing to help students:

1. Instructor (from Canada): What is an exploitation system?

2. Student 1 (to local tutor): The question is addressed to you, Monsieur

3. Local tutor (protesting): Oh no! The question is addressed to you, students!

4. Student 2: We do not know Monsieur. We came here to learn about it.

5. Local tutor:

How are we supposed to know before we learn about it?

$\begin{array}{ll}\text { 6. Instructor (from Canada): } & \text { I am still waiting for your answer... }\end{array}$

As revealed in many other episodes, students seemed to enjoy challenging their local tutor. Overall, this interaction episode mobilized students' attention for 4 minutes and 23 seconds. During this time, one student was bending over the computer keyboard in the back of the classroom struggling to type in a written answer (see Figure 1). A few classmates who were paying some attention to his efforts came up with contradictory suggestions to assist him. Some mocked his spelling mistakes. Rather than helping, these actions contributed to confusing him and slowing down his composition efforts and WPM counts.

This episode highlighted the extent to which local tutors seem ill-prepared and poorly motivated to handle their important student support, facilitator, and mediator roles. What is more, they had no interaction whatsoever with the distant instructors, whose teaching they were supposed to complement in the field. The episode related above happened after the settlement of a work dispute that forced the AVU management to pay arrears to in-service local tutors and to hire more local tutors. 


\section{The Way Forward}

\section{Sound Pedagogy instead of "Technological Silver Bullets"}

Findings from this study have shed light on some of the reasons why IDE projects have failed to live up to their lofty promises of cost-effectiveness, cost-efficiency, and economy of scale in SSA. Despite the remarkable potential of IDE to improve learning when informed by learning theories and principles of instructional design, results from this study show how disregard for these factors resulted in technological, pedagogical, administrative, and political problems that crippled instructor-to-student interaction and thus the learning process. The low success rate and high attrition rate within IDE projects in SSA are two eloquent indicators of their poor performance. For example, the success rate of the first AVU cohort in computer science at the AVU was as low as 37\% (Latulippe, 2004) and only 36\% (18 out of the 50) of in-service professional nurses who had registered at the UNFM Ouagadougou in 2005 managed to graduate in 2007 (Ilboudo, 2007).

These numbers are consistent with the drop-out rate in developed countries. The worst estimations contend it is as high as 70-80\% (Flood, 2002), the most conservative downplay it to 10-20\% higher than on-campus learning (Carr; Frankola, 2001). Considering Tinto's contention (1982) that on-campus attrition has held constant between $40-45 \%$ over the last century this brings the conservative drop-out figure in developed countries to somewhere between $50-65 \%$.

In addition, according to Frankola (2001), most of the reasons invoked by online learners from developed countries for dropping out are strikingly similar to the ones highlighted throughout this study: lack of time, lack of student support, lack of management oversight, poorly designed courses, substandard/inexperienced instructors, and individual learning preferences.

However, given the number of additional technological, socio-economical, political, and cultural challenges highlighted in this study, the similarities between online learning in SSA and in developed countries might be misleading if it is not situated in its systemic political and ideological landscape. Although it is important to salute some genuine success stories that have helped people in developing countries tremendously over the last half century, most foreign aidfunded projects in SSA seem to be designed and implemented according to donor countries' "massive assumptions" (Foster, 1967) and self-interest (Easterly 2007). Thus, although they are poorly accountable, they tend to inflate their outcomes and "tell performance stories" (Mayne, 2004), which seems to have been the case with IDE projects in SSA (Asunka, 2008; Muhirwa, 2008). For example, the AVU continued to paint a rosy picture of its performance and prospects in SSA despite its numerous weaknesses and the recent interventions by funders to resuscitate it.

Findings from this study are consistent with the conclusions reached by the Working Group on Canada's Policy with Regard to Agricultural Biotechnology and Developing Countries (2005). While recognizing the potential of science and technology to foster the development of SSA, the Working Group issued this warning: 
As with most interventions, however, "context" is everything. If new technologies are introduced into a foreign environment in the absence of a clearly understood demand and careful preparation (...) there is every risk that the tool will take priority over the purpose. (p.1)

\section{Revisiting the Educational Potential of Traditional Technologies?}

It appears that history has repeated itself. Head (1974) deplored how costly technical equipment siphoned the lion's share of funding destined to the development of radio in SSA to the detriment of research on its remarkable educational and social mobilization potential. More than three decades of hindsight give ample credibility to Berman (2008) when she argues the following:

Instead of merely transposing western approaches to distance education in developing countries, the developed world can learn from uses of radio in developing countries, and that the medium deserves greater attention as a means of giving educational opportunity to rural, isolated people worldwide. (p.

1)

This argument echoes my own experience. While growing up in the African Great Lakes region during the seventies and eighties, I had the privilege to witness first-hand the huge audience for radio dramas such as the Kapalata series, broadcast in Swahili from Radio Bukavu (South Kivu province, DRC), Ninde?, and Ikinamico, broadcast respectively by Radio Burundi and Radio Rwanda. The plots of these dramas would linger for weeks, feeding conversation, amusement, or argument at school, in the fields, or at social gatherings. Unfortunately, this potential was hardly exploited in any meaningful manner to address the myriad of development problems that plagued the region. In 1994 the world was horrified to learn how devilishly efficient a hate radio campaign was in fuelling the killings during the Rwandan genocide. In just three months, hundreds of thousands of Rwandans had been killed. More recently and in much less tragic circumstances, I witnessed the extent to which radio was an incomparably efficient tool for public education and social mobilization while working as media, advocacy and research coordinator for a Canadian International Development Agency (CIDA)-funded project to fight against child trafficking in Mali, Burkina Faso, Guinea, and Côte d'Ivoire.

With political will, pedagogy, instructional design know-how, and only a fraction of the resources dedicated to ICT-based IDE, it would be possible to transform traditional media such as radio and video into productive educational technologies in SSA and in oral cultures around the world. 


\section{References}

Amutabi, M.N., \& Oketch, M.O. (2003). Experimenting in distance education: The African Virtual University (AVU) and the paradox of World Bank in Kenya. International Journal of Educational Development, 23, 57-73.

Asunka, S. (2008). Online learning in higher education in sub-Saharan Africa: Ghanaian university students experiences and perceptions. International Review of Research in Open and Distance Learning, 9(3). Retrieved Jan, 2009, from http://www.irrodl.org/index.php/irrodl/article/view/588/1136

Assié-Lumumba, N. T. (Ed.). (2004). Cyberspace, distance education and higher education in developing countries: Old and emergent issues of access, pedagogy and knowledge production. International Studies in Sociology and Social Anthropology, 94. Leiden: Brill.

Bateman, P. (2004). A position paper for the instructional technology and design unit at the AVU. Nairobi: The AVU.

Berman, S.D. (2008). The return of educational radio? International Review of Research in Open and Distance Learning, 9(2). http://www.irrodl.org/index.php/irrodl/article/view/563/1038

Bloom, B.S., Englehart, M.D., Furst, E.J., Hill, W.H., \& Krathwohl, D.R. (1956). Taxonomy of educational objectives: The classification of educational goals. Handbook I: Cognitive domain. White Plains, NY: Longman.

Carr, S. (2000). As distance education comes of age, the challenge is keeping the students. The Chronicle of Higher Education, 23, p. A39. Retrieved November, 2008, from http://chronicle.com/free/v46/i23/23a00101.htm

Clark, J.M., \& Paivio, A. (1991). Dual coding theory and education. Educational Psychology Review, 3(3) 149-170.

Dhanarajan, G. (2001). Distance education: Promise, performance and potential. Open Learning 16(1).

Easterly, W. (2006). The white man's burden: Why the West's efforts to help the rest have done so much ill and so little good. New York: Penguin Press.

Erikson, F. (2006). Definition and analysis of data from videotape: Some research procedures and their rationales. In J. L. Green, G. Camilli, \& P. B. Elmore (Eds.), Complementary methods in education research. Mahwah, NJ: Lawrence Erlbaum. 
Flood, J. (2002) Read all about it: Online learning facing $80 \%$ attrition rates.

Turkish Online Journal of Distance Education (TOJDE), 3(2). Retrieved October, 2008, from http://tojde.anadolu.edu.tr/tojde6/articles/jim2.htm

Foster, G. (1967). Applied anthropology. Boston: Little, Brown and Company.

Frankola, K. (2001). Why online learners dropout. Workforce, October 10, 53-63.

Fulford, C., \& Zang, S. (1993). Perceptions of interactions: The critical predictor in distance education. The American Journal of Distance Education, 7(3), 8-21.

Gakio, K. (2006). African tertiary institutions connectivity survey (ATICS). 2006 report. Ottawa: IDRC. Retrieved August, 2009, from http://www.aau.org/renu/docs/ATICS2006.pdf

Gunawardena, L., Lowe, C., \& Anderson, T. (1997). Interaction analysis of a global online debate and the development of a constructivist interaction analysis model for computer conferencing. Journal of Educational Computing Research, 17(4), 395-429.

Gunawardena, C.N., \& Zittle, F.J. (1997). Social presence as a predictor of satisfaction within a computer-mediated conferencing environment. The American Journal of Distance Education, 11(3), 8-25.

Hannafin, M.J. (1989). Interaction strategies and emerging instructional technologies: Psychological perspectives. Canadian Journal of Educational Communication, 18(3), 167-169.

Head, S. W. (1974) (Ed.). Broadcasting in Africa: A continental survey of radio and television. Philadelphia: Temple University Press.

Heath, S. B. (1983). Ways with words: Language, life, and work in communities and classrooms. New York: Cambridge University Press.

Hillman, D.C., Willis, D.J., Gunawardena, C.N. (1994). Learner-interface interaction in distance education. An extension of contemporary models and strategies for practitioners. The American Journal of Distance Education, 8(2), 30-42.

Ilboudo, J.B. (2007). Université de Ouagadougou - Université Numérique Francophone Mondiale: Un bel exemple de coopération interuniversitaire. Retrieved August, 2009, from http://www.univouaga.bf/html/actualites/cq_de_presse/articles/frSignatureConvention_UoUnfm.html

Insung, J., Seonghee, C., Cheolil, L., \& Junghoon, L. (2002). Effects of different types of interaction on learning achievement, satisfaction and participation in web-based 
instruction. Innovations in Education and Teaching International, 39(2), 153-162.

Isokoski, P., \& Linden, T. (2004). Effect of foreign language on text transcription performance: Finns writing English. Procceedings of NordiCHI, 109-112.

Jorgensen, D.W. (2006). One size doesn't fit all: Achieving accountability through application of learning patterns. In R. R. Sims \& J. Sims (Eds.), Learning styles and learning: A key to meeting the accountability demands in education. New York: Nova Science Publishers.

Karat, C.M., Havelson, C., Horn, D., \& Karat, J. (1999). Patterns of entry and correction in large vocabulary continuous speech recognition systems. CHI 99 Conference Proceedings, USA, 568-575.

Kress, G. (2003). Literacy in the new media age. London: Routledge.

Latulippe, J.G. (2004). VISAF I: Le Virtuel au service de l'Afrique francophone: Évaluation du projet VISAF. Ottawa: AUCC/ACDI.

Leahy, W., Cooper, G., \& Sweller, J. (2004). Interactivity and the constraints of cognitive load theory. In A. Peacock \& A. Cleghorn (Eds.), Missing the meaning: The development and the use of print and non-print text materials in diverse school settings. New York: Palgrave MacMillan.

Lentell, H . (2003). The importance of the tutor in open and distance learning. In A. Tait \& A. Mill (Eds.), Rethinking learner support in distance education (pp. 64-75). London: Routledge.

Loiret, P.- J. (2005). L'Université virtuelle africaine, histoire d'une mise en scène. Mémoire de maîtrise non publié. Université de Rouen, France.

Matthewson, C. (1994). Whose development, whose needs? Distance education practice and politics in the South Pacific. Journal of Distance Education/Journal de l'Enseignement à Distance, 9(2).

Mayne, J. (2004). Reporting on outcomes: Setting performance expectations and telling performance stories. The Canadian Journal of Program Evaluation, 19(1), 31-59.

Moodie, T. (2003) Alternative ways of knowing. Doing justice to non-Western intellectual traditions in a postmodern era. Journal of Education, 31. Retrieved Nov, 2008, from http://www.ukzn.ac.za/joe/joepdfs/joe\%2031\%20moodie.pdf

Moore, M.G. (1997). Theory of transactional distance. In D. Keegan (Ed.), Theoretical principles of distance education (pp. 22-38). London: Routledge. 
Moore, M.G. (1989). Editorial: Three types of interaction. The American Journal of Distance Education, 3(2), 1-6.

Muhirwa, JMK (2008). The performance of foreign aid-funded distance learning projects in sub-Saharan Africa: A Qualitative analysis. Unpublished doctoral dissertation, Concordia University, Montreal, Canada.

Munene, I. I. (2007). Experimenting in distance education: The African Virtual University (AVU) and the paradox of World Bank in Kenya-A rejoinder. International Journal of Educational Development, 27(1), 77-85.

Nastasi, B.K. (1999). Audiovisual methods in ethnography. In J.J. Schensul, M.D. LeCompte, B.K. Nastasi, \& S.T. Borgatti (Eds.), Enhanced audiovisual methods: Audiovisual techniques, focused groups, interviews and elicitation techniques (pp. 1-50). London: Altamira.

Reeves, T. (1999). Keynote address. ED-MEDIA 1999 World Conference on Educational Multimedia, Hypermedia and Telecommunications, Seattle, Washington.

Rogoff, B. (1995). Observing sociocultural activity on three planes: Participatory appropriation, guided participation, and apprenticeship. In J. Wertsch, P. Del Rio, \& A. Alvarez (Eds.), Sociocultural study of mind (pp. 139-164). New York: Cambridge University Press.

Steiner, R., Nyaska, T., Jensen, M., \& Karanja, G. (2004). African tertiary institution connectivity survey (ATICS). Washington, DC: The World Bank Institute. Retrieved October, 2008, from http://www.dgroups.org/groups/cgiar/InternetAfrica/docs/ATICS2004Report.pdf?ois=no

Sy, J. H. (2004). Partnership in higher education in Africa: Communication implications beyond the 2000s. In N. T. Assié-Lumumba (Ed.), Cyberspace, distance education and higher education in developing countries: Old and emergent issues of access, pedagogy and knowledge production (pp 57-90). Leiden: Brill.

Sweller, J., Van Marriënboer, J.J.G., \& Pass, F.G.W.C. (1998). Cognitive architecture and instructional design. Educational Psychology Review, 10, 251-296.

The Working Group on Canada's Policy with Regard to Agricultural Biotechnology and Developing Countries. (2005). No more technological "silver bullets": A policy brief on Canada's role in Africa's agricultural underdevelopment. Retrieved March, 2008, from http://www.interpares.ca/en/publications/pdf/no_more_silver_bullets.pdf

Tinto, V. (1982). Limits of theory and practice in student attrition. Journal of Higher Education, 53(6), 687-700. 
Tisher, R.P. (1972). Classroom interaction analysis: The new religion? Research in Science Education, 2(1), 35-49.

Vygotsky, L.S. (1978). Mind in society: The development of higher psychological processes. Cambridge, MA: Harvard University Press.

Yacci, M. (2000). Interactivity demystified: A structural definition for distance education and intelligent CBT. Educational Technology, 40(4), 5-16. 